\title{
Duas espécies novas de Dendroblatta Rehn (Blattellidae) coletados no Acre (Brasil) em ninhos de vespas
}

\author{
Sonia Maria Lopes ${ }^{1}$
}

${ }^{1}$ Departamento de Entomologia, Museu Nacional, Universidade Federal do Rio de Janeiro, Quinta da Boa Vista, 20940-040 São Cristóvão-RJ, Brasil.sonialf@acd.ufrj.br

\begin{abstract}
Two new species of Dendroblatta Rehn (Blattellidae) collected from Acre (Brazil) in wasps' nests. D. falcifera sp. nov. and D. moratoi sp. nov., collected inside the wasps' nests of the family Sphecidae serving as preys for the immature forms, are described from the State of Acre, Brazil.
\end{abstract}

KEYWORDS. Blattaria; morphology; taxonomy; wasps'nest.

RESUMO. Duas espécies novas de Dendroblatta Rehn (Blattellidae) coletadas no Acre (Brasil) em ninhos de vespas. D. falcifera sp. nov. e D. moratoi sp. nov. coletadas no interior de ninhos de vespas da família Sphecidae, servindo como presas para imaturos, são descritas do Estado do Acre, Brasil.

PALAVRAS-CHAVE. Blattaria; morfologia; ninhos de vespas; taxonomia.

Dendroblatta foi descrito por Rehn (1916), caracterizado morfologicamente pelo fêmur I que apresenta na face ânteroventral, uma série de espinhos decrescendo subitamente em tamanho (tipo B), na face póstero-ventral um grupo de espinhos apicais alongados; pulvilos somente no quarto artículo tarsal e arólios presentes; tégminas muito desenvolvidas nos machos e moderadamente reduzidas nas fêmeas, com setores discoidais oblíquos; nas asas a veia ulnar com todos os ramos completos, atingindo a margem distal; abdome, nos machos, podendo apresentar ou não glândulas medianas.

O gênero Dendroblatta tem como espécie-tipo, D. sobrina Rehn, 1916; ocorre da América Central (Nicarágua, Costa Rica e Panamá) à América do Sul (Trinidad, Venezuela, Guiana, Suriname, Guiana Francesa, Colômbia, Peru e no Brasil nos Estados do Amapá, Amazonas, Pará, Acre, Rondônia, Bahia e Rio de Janeiro).

Os espécimes foram analisados morfologicamente de acordo com as técnicas utilizadas e descritas em Lopes \& Oliveira (2000) e depositados na coleção do Departamento de Entomologia do Museu Nacional, Universidade Federal do Rio de Janeiro (MNRJ). A classificação taxonômica e a terminologia seguiram os conceitos propostos por Mckittrick (1964).

Após análise, as placas e peças da genitália foram guardadas em microtubos, contendo glicerina e devidamente acondicionados junto ao exemplar respectivo, montado em alfinete entomológico, técnica desenvolvida por Gurney et al. (1964).

As baratas aqui analisadas foram predadas por vespas, para servirem de alimento aos imaturos em seus ninhos. Essas vespas, as do gênero Podium Fabricius, 1804, fazem seus ninhos em cavidades em troncos secos ou apodrecidos, em ninhos de outras vespas ou em colunas nas casas. A fim de manter sua prole capturam baratas e as ferroam no tórax ou abdome, imobilizando-as. Em seguida, em geral, cortam as antenas das mesmas para que seja liberada secreção e, posteriormente venham a servir de alimento aos imaturos, que eclodirão dos ovos colocados no ninho (Bohart \& Menke, 1976).

\section{Dendroblatta falcifera sp. nov.} (Figs. 1-7)

Diagnose. Holótipo macho. Coloração geral castanha. Pronoto e cabeça castanho-claros. Pronoto na região basal, na margem do entorno e nas manchas irregulares castanhoescuro (Fig. 2), olhos negros; vértice amarelado; clípeo claro com duas pequenas pontuações látero-basais castanhoescuras (Fig. 1). Campos discoidal e anal da tégmina e as bases de inserção dos espinhos nas pernas castanho-escuros. Palpos e antenas com tomentosidade dourada. Tégminas bicoloridas. Campo marginal e parte mais externa do campo escapular castanho-claro amarelados; tronco inicial de todas as nervuras quase negro. Pulvilos e arólios esbranquiçados.

Dimensões (mm). Holótipo macho. Comprimento total 18,0; comprimento do pronoto 4,0; largura do pronoto 6,0 ; comprimento da tégmina 16,0; largura da tégmina 5,5.

Cabeça triangular; vértice exposto, espaço interocular estreito, medindo cerca de um quarto da distância entre as bases das inserções antenais. Ocelos bem definidos. Antenas longas, tomentosas, ultrapassando o ápice do abdome. Palpos maxilares desenvolvidos, primeiro e segundo artículos pequenos, terceiro artículo maior que o quarto, quinto artículo dilatado, tomentoso e pouco menor que o terceiro.

Tórax. Pronoto convexo, oval e transverso, de ápice e base retos, abas laterais amplas, com entorno arredondado. 
Tégminas desenvolvidas, longas, ultrapassando o ápice dos cercos; campo marginal levemente côncavo e bem marcado; campo escapular estreito e alongado; campo discoidal alargado médio-apicalmente; campo anal curto. Pernas desenvolvidas e espinhosas. Fêmur I na face ântero-ventral com uma série de seis ou sete espinhos fortes e espaçados, da base até a região mediana, seguida de outra série de espinhos pequenos e muito próximos uns dos outros até o ápice, onde se encontra dois apicais grandes e fortes, sendo o último o dobro do tamanho do anterior (tipo B). Fêmur II e III com as faces antero e pósteroventrais semelhantes, apresentando espinhos fortes e espaçados em toda a sua extensão, com um apical maior. Pulvilos pequenos presentes nos quatro artículos; unhas simples e simétricas; arólios presentes, porém pouco desenvolvidos.

Abdome sem modificação tergal. Placa supra-anal ciliada nos bordos e projetada entre os cercos com reentrância mediana marcante; cercos desenvolvidos e ciliados (Fig. 4). Placa subgenital ciliada, assimétrica apresentando dois estilos muito desenvolvidos e assimétricos, derivados dos bordos laterais da placa, três estilos acessórios, sendo dois convergentes entre si no meio da placa e um menor do lado esquerdo (Fig. 3). Falômero esquerdo complexo em forma de um Y invertido, apresentando duas projeções laterais assimétricas, sendo uma delas maior, e estrutura mediana bastante esclerotinizada (Fig. 7). Falômero direito em forma de gancho apicalmente (Fig. 5). Esclerito mediano desenvolvido, simples, apresentando o ápice em forma de uma foice, com várias proeminências ventralmente (Fig. 6).

Etimologia. O nome é alusivo à configuração do ápice do esclerito mediano em forma de foice.

Holótipo macho. BRASIL, Acre, Senador Guiomard, Reserva Catuaba, $\left(10^{\circ} 4^{\prime} \mathrm{S}\right.$ e $\left.67^{\circ} 30^{\prime} \mathrm{W}\right)$, Elder F. Morato col. (em ninhos de vespas Sphecidae Podium, ninho 2.291/1; parátipo fêmea; dados iguais ao do Holótipo, ninho 2.614/2 (MNRJ).

\section{D. moratoi sp. nov.}

(Figs. 8-14)

Diagnose. Coloração geral castanha. Cabeça, pronoto e tégminas nos campos marginal e escapular, de coloração castanho-clara. Coloração castanho-escura: na fronte (Fig. 8); em dois pontos do clípeo lateralmente; no espaço interocular, na área basal do pronoto, em manchas irregulares, no disco central (Fig. 9); nas tégminas no tronco inicial de todas as veias e nos campos discoidal e anal. Vértice amarelado; palpos claros com tomentosidade dourada e dorso mais escuro. Pernas com a base de inserção dos espinhos escura. Pulvilos e arólios esbranquiçados.

Dimensões (mm): Holótipo macho. Comprimento total 20,0; comprimento do pronoto 4,0; largura do pronoto 5,5; comprimento da tégmina 17,0; largura da tégmina 5,0.

Cabeça subtriangular. Vértice exposto, espaço interocular estreito medindo cerca de um quarto da área entre as inserções antenais. Antenas longas, tomentosas, ultrapassando o ápice do abdome. Palpos maxilares desenvolvidos e tomentosos, os
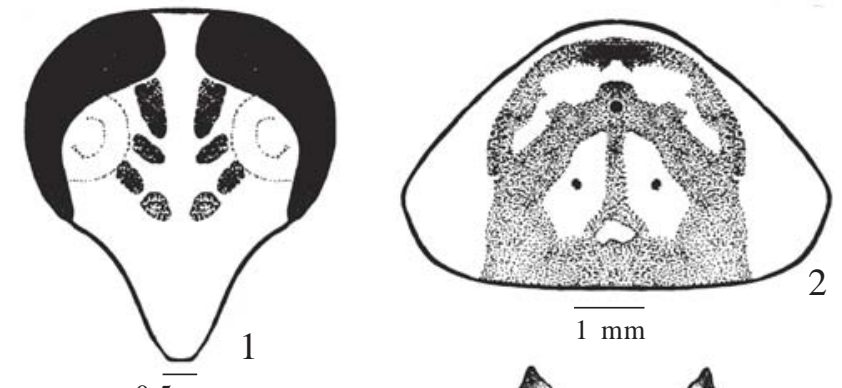

$0, \overline{5 \mathrm{~mm}}$


4

Figs. 1-7. Dendroblatta falcifera sp. nov., holótipo macho. 1, cabeça, vista ventral; 2 , pronoto, vista dorsal; 3 , placa subgenital, vista ventral; 4, placa supra-anal, vista dorsal; 5, falômero direito, vista dorsal; 6, esclerito mediano, vista dorsal; 7, falômero esquerdo, vista dorsal.

três primeiros artículos reduzidos em tamanho, quarto artículo levemente maior que o quinto este último dilatado no ápice.

Tórax. Pronoto (Fig. 9) convexo, oval e transverso, abas laterais amplas e arredondadas. Tégminas desenvolvidas, longas, ultrapassando o ápice dos cercos; campo marginal levemente côncavo e bem marcado; campo escapular convexo, campo discoidal alargado médio-apicalmente, campo anal curto. Pernas desenvolvidas e espinhosas. Fêmur I, na face ântero-ventral, com uma série de seis espinhos fortes e espaçados da base até a região mediana, seguida de outra série de espinhos pequenos e muito próximos uns aos outros até o ápice, onde se encontram dois apicais grandes e fortes, sendo o último o dobro do tamanho do anterior. Fêmures II e III com faces antero e póstero-ventrais semelhantes, apresentando espinhos fortes e espaçados em toda a sua extensão com um apical pouco maior. Pulvilos presentes somente no quarto artículo tarsal. Unhas simples e simétricas; arólios presentes embora pouco desenvolvidos.

Abdome sem modificação tergal. Placa supra-anal ciliada, 

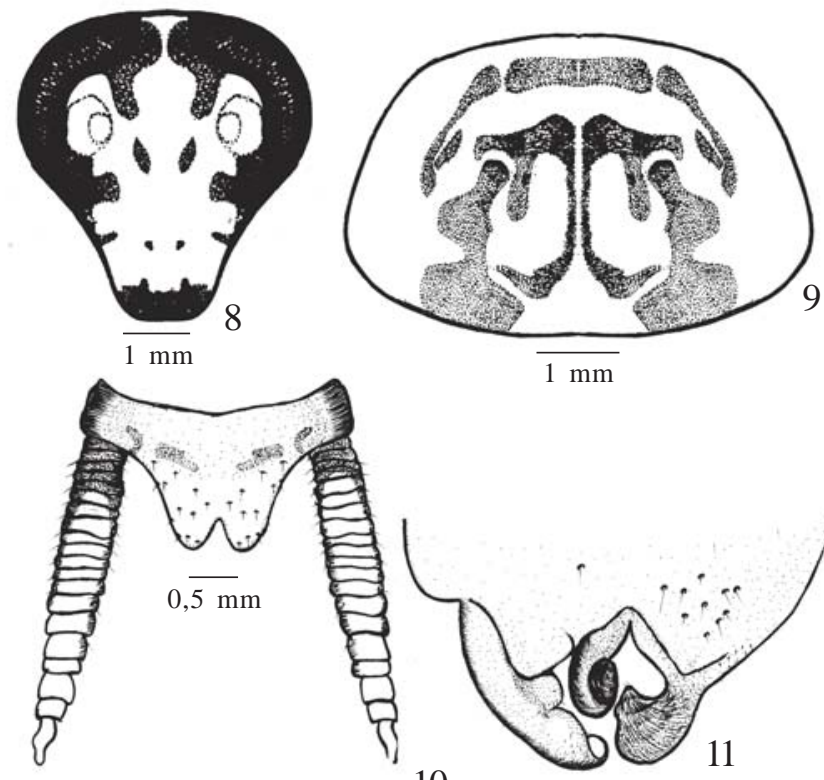

$\mathrm{mm}$

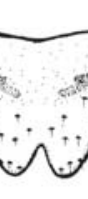

$0, \overline{5 \mathrm{~mm}}$

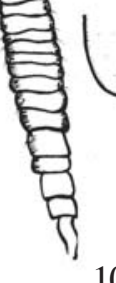

10

$$
\overline{1 \mathrm{~mm}}
$$

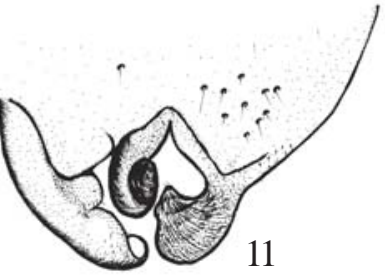

$\overline{0,5 \mathrm{~mm}}$
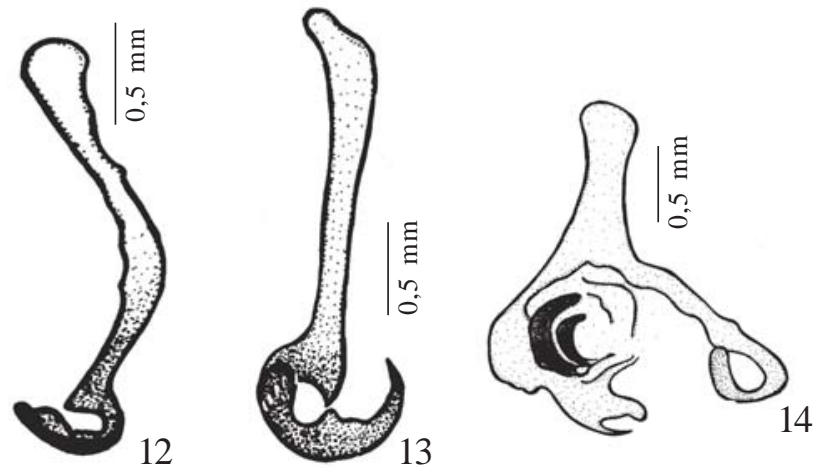

Figs. 8-14. Dendroblatta moratoi sp. nov. holótipo macho. 8, cabeça, vista ventral; 9, pronoto, vista dorsal; 10, placa supra-anal, vista dorsal; 11, placa subgenital, vista ventral; 12 , falômero direito, vista dorsal; 13, esclerito mediano, vista dorsal; 14, falômero esquerdo, vista dorsal.

projetada entre os cercos, apresentando acentuada reentrância medianamente; cercos desenvolvidos e ciliados (Fig. 10). Placa subgenital assimétrica apresentando dois estilos alargados nos bordos da placa convergindo para a região mediana da mesma e um estilo acessório em forma de pêndulo desenvolvido entre os estilos citados anteriormente
(Fig. 11). Falômero esquerdo em forma de $\mathrm{Y}$ invertido, apresentando duas projeções assimétricas, uma delas mais desenvolvida que a outra e estrutura mediana semicircular muito esclerotinizada (Fig. 14); falômero direito em forma de gancho (Fig. 12); esclerito mediano desenvolvido apresentando o ápice em forma de foice com uma acentuada projeção ventralmente (Fig. 13).

Holótipo macho. BRASIL, Acre, Senador Guiomard, Reserva

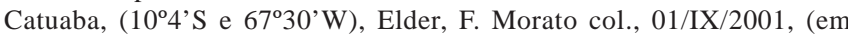
ninhos de vespas Sphecidae, Podium sp, ninho 382/3); parátipo macho, dados iguais ao do holótipo, 24/VIII/2001, (ninho 300/4); parátipo fêmea: dados iguais ao holótipo, 04/II/2002, (ninho 1285/2).

Etimologia: O nome é dado em homenagem ao coletor, pela sua contribuição ao enriquecimento da coleção de Blattaria do Departamento de Entomologia do Museu Nacional.

Comentário. As duas espécies aqui descritas se distinguem pela configuração das placas genitais (supra-anal e subgenital) do macho, bem como pela configuração do esclerito mediano, dos falômeros esquerdo e direito, como apresentado na descrição das mesmas.

Agradecimentos. Ao biólogo Edivar Heeren de Oliveira (Museu Nacional, UFRJ) pelas sugestões e revisão deste trabalho. Ao Prof. Elder F. Morato (Universidade Federal de Minas Gerais) pelo material coletado e enviado para identificação. Ao Conselho Nacional de Desenvolvimento Científico e Tecnológico (CNPq) e a Fundação de Amparo à Pesquisa do Estado do Rio de Janeiro (FAPERJ) pelo apoio financeiro.

\section{REFERÊNCIAS}

Bohart, R. M. \& Menke, A. S. 1976. Sphecid Wasps of the World: A Generic Revision. Berkeley University of Chicago Press. 695p.

Gurney, A. B.; J. P. Kramer \& G. C. Steyskal. 1964. Some Techniques for the Preparation, Study and Storage in Microvials of Insect Genitalia. Annals of the Entomological Society of America 57: $240-242$.

Lopes, S. M. \& E. H. Oliveira. 2000. Espécie nova de Eublaberus Hebard, 1919 do Estado de Goiás, Brasil e notas sobre E. marajoara Rocha e Silva-Albuquerque, 1972 (Blaberidae, Blaberinae). Boletim do Museu Nacional, N. S., Zoologia 433: 1-5.

Mckittrick. F. A. 1964. Evolutionary studies of cockroaches. Cornell Experiment Station Memoir 389: 1-197.

Rehn, J. A. G. 1916. The Stanford Expedition to Brazil, 1911. J. C. Branner, Director Dermaptera and Orthoptera I. Transactions of the American Entomological Society 42: 215-308. 